\title{
DEVELOPING GYRFALCON SURVEYS AND MONITORING FOR ALASKA
}

\author{
Mark R. Fuller ${ }^{1}$, Philip F. SchempF ${ }^{2}$, And Travis L. Booms ${ }^{3}$ \\ ${ }^{1}$ US Geological Survey, Forest and Rangeland Ecosystem Science Center, and \\ Boise State University - Raptor Research Center \\ 970 Lusk Street, Boise, ID 83706, USA. E-mail: mark_fuller@usgs.gov \\ ${ }^{2}$ US Fish and Wildlife Service, Migratory Bird Management Office (retired) \\ 3000 Vintage Boulevard., Suite 240, Juneau, AK 99801, USA \\ ${ }^{3}$ Alaska Department of Fish and Game, Wildlife Diversity Program \\ 1300 College Road, Fairbanks, AK 99701, USA
}

\begin{abstract}
We developed methods to monitor the status of Gyrfalcons in Alaska. Results of surveys and monitoring will be informative for resource managers and will be useful for studying potential changes in ecological communities of the high latitudes. We estimated that the probability of detecting a Gyrfalcon at an occupied nest site was between $64 \%$ and $87 \%$ depending on observer experience and aircraft type (fixed-wing or helicopter). The probability of detection is an important factor for estimating occupancy of nesting areas, and occupancy can be used as a metric for monitoring species' status. We conclude that surveys of nesting habitat to monitor occupancy during the breeding season are practical because of the high probability of seeing a Gyrfalcon from aircraft. Aerial surveys are effective for searching sample plots or index areas in the expanse of the Alaskan terrain. Furthermore, several species of cliff-nesting birds can be surveyed concurrently from aircraft. Occupancy estimation also can be applied using data from other field search methods (e.g., from boats) that have proven useful in Alaska. We believe a coordinated broad-scale, inter-agency, collaborative approach is necessary in Alaska. Monitoring can be facilitated by collating and archiving each set of results in a secure universal repository to allow for statewide meta-analysis. Received 16 September 2011, accepted 10 November 2011.
\end{abstract}

Fuller, M. R., P. F. SCHEMPF, AND T. L. Booms. 2011. Developing Gyrfalcon surveys and monitoring for Alaska. Pages 275-282 in R. T. Watson, T. J. Cade, M. Fuller, G. Hunt, and E. Potapov (Eds.). Gyrfalcons and Ptarmigan in a Changing World, Volume I. The Peregrine Fund, Boise, Idaho, USA. http://dx.doi.org/10.4080/gpcw.2011.0129

Key words: survey, monitoring, Gyrfalcon, Falco rusticolus.

WE PARTICIPATED IN AN INITIATIVE of the US Fish and Wildlife Service (FWS) to develop a strategy to monitor the status of Gyrfalcons in Alaska. In the United States, Gyrfalcons
(Falco rusticolus) breed only in Alaska where the species might be affected by environmental changes, thus indicating the need to monitor their population status there. However, a large 
portion of potential Gyrfalcon habitat in Alaska, as well as North America, has not been surveyed (Booms et al. 2008a), and there was no strategy for monitoring the species' population status in Alaska. In September 2002 at the North Pacific Migratory Bird Conference (Breadloaf, Vermont, USA), Kent Wohl (FWS, Alaska) requested the development of a monitoring plan for Gyrfalcons.

\section{METHODS}

Developing the Strategy.-There was incomplete information about the species' range in Alaska (Swem et al. 1994) and a need to learn about differences in the ecology and abundance of the species across approximately $1,481,000 \mathrm{~km}^{2}$ and diverse landscapes of the state. During September 2002, at the $5^{\text {th }}$ N. American Ornithological Conference, we began discussions about Gyrfalcons with Alaskan raptor biologists Carol McIntyre, Ted Swem, and Kim Titus. Additionally, we began reviewing literature, corresponding with additional colleagues, and investigating potential study sites to address some of the information needs. Next, in September 2003 at the meeting of the Raptor Research Foundation, we convened participants from the United States and Canada to discuss material for a study plan and monitoring strategy.

We used the following criteria as a guide for the goal of detecting change in the population: ensure the ability to detect a $50 \%$ reduction in the count or index over a 25 -year period with alpha $=0.10$ and beta $=0.20$. Lewis and Gould (2000) discuss the use of such criteria as applied to the counts of migrant raptors. We identified two objectives for our initial efforts: develop effective search methods and survey designs that are feasible and effective for the various landscapes of Alaska, and identify where to allocate survey and monitoring sampling effort among the regions of the Gyrfalcon's breeding range in Alaska.
The literature and our discussions with colleagues indicated that the most common surveys conducted for Gyrfalcons in Alaska were for nesting activity (e.g., Cade 1960, Roseneau 1972, Mossop and Hayes 1994, Swem et al. 1994). Additionally, we obtained information about successful use of field procedures (e.g., air, boat) for multi-year surveys of nesting Gyrfalcons (White and Sherrod 1973, Ambrose et al. 1988). Based on the information we gathered, we tested the potential for monitoring surveys of nesting activity.

To test the efficacy of nest surveys for monitoring a decrease in Gyrfalcons' nest occupancy, we used the program MONITOR to examine results from multi-year surveys in the Colville River, Alaska and Northwest Territories, Canada (Swem et al. 1994, Shank and Poole 1994). The data used from the Colville River were: mean number of occupied nests/yr $=16 ; \mathrm{SD}=6.1$; years surveys conducted $=11$; number of times per year surveys were conducted $=2$. We asked if this survey was able to detect a $10 \%$ decline in the population given the above information, and an alpha level of 0.15 using a two-tailed test. The program results indicated that from these Colville River survey data we were able to detect a $10 \%$ population decline with an $81 \%$ confidence (power level). Similarly, for Northwest Territories, Canada, we could detect such a decline with $94 \%$ confidence. Because these survey data met our monitoring criteria, we proceeded to gather data for a survey and monitoring strategy based on aerial surveys of Gyrfalcon nesting areas and using occupancy (Geissler and Fuller 1986) as a monitoring metric.

Research.-Travis Booms undertook research for his Ph.D. program (Booms 2010) at the University of Alaska, and our main study area was the Yukon Delta National Wildlife Refuge (YDNWR). There, we based our research on the early work of White and Springer (1965) and the ongoing surveys and fieldwork led by 
Brian McCaffery (McCaffery et al. 2011). This region in western Alaska contains the delta of two large rivers, the Yukon River and the Kuskowkim River, and three areas in which Gyrfalcons nest and had been surveyed previously. We relied on McCaffery, other YDNWR staff members, and several volunteers to help gather the data used by Booms and colleagues to produce the results presented in Booms et al. (2010b) and presented here in part. We used occupancy estimation and modeling procedures of MacKenzie et al. (2006) to estimate the probability of detecting Gyrfalcons at historical nest areas.

During the period we were conducting surveys for nest occupancy, Booms and colleagues studied the known distribution of Gyrfalcons in Alaska and modeled areas they predicted other Gyrfalcons likely were nesting (Booms et al. 2009). Further, Booms et al. (2008b, 2011a) studied nest site fidelity and dispersal. The results of these projects are the basis for developing a strategy to monitor Gyrfalcons in Alaska.

\section{RESULTS AND DiscuSSION}

On the YDNWR, our aerial surveys for the presence of a Gyrfalcon at known nest sites resulted in a probability of detection ranging from $65-85 \%$. Factors that were associated with differences in detectability included different aircraft (helicopters and fixed-wing aircraft) and different observers (Booms et al. 2010). Given the vast, remote geography of Alaska and the span of time needed for longterm monitoring (e.g., 20-30 years), we expect that many persons of varied experience will be involved in surveys for Gyrfalcons using a variety of search methods in many different habitats. For biologists to compare survey results from different survey efforts and time frames, and to synthesize the results for assessing Gyrfalcon status, it is important to use estimates of occupancy that have been derived by incorporating probability of detection. When a nest site is occupied and a bird(s) is as conspic- uous as indicated by our detection probabilities (i.e., $65 \%$ to $85 \%$ ), we expect that two replicate searches of a sample of the survey area will produce estimates of detectability that can be used to model occupancy (MacKenzie et al. 2006), which in turn can be used as a metric of population status.

A change in nest site occupancy can serve as a warning that the number of falcons in the population might be changing. It is useful to monitor occupancy, especially when it is impractical to consistently gather data about reproduction and survival. Insight into the likelihood of a change in population size can be had by studying a sample of the occupancy survey areas for reproduction and survival data that can be used in analyses of population dynamics (Williams et al. 2002).

Booms et al. (2009) modeled the distribution of likely Gyrfalcon nesting areas across Alaska, and they predicted that $75 \%$ of the state would contain essentially no nesting, while about $7 \%$ would be highly likely nesting range. The predicted high category of occurrence $(>80 \%)$ was patchy and widely dispersed, and located in southwest, west, northwest, and northern Alaska (Figure 1).

The population dynamics of Gyrfalcons might differ among the various ecological conditions found across Alaska. Therefore, it is important to allocate survey and monitoring effort to sample the nesting range. The predictions of the nesting distribution model can be used initially as a basis for sample allocation. This will accomplish two important objectives: 1) the applicability of the model can be tested and made more rigorous with additional field data, and 2) survey results can be generated for parts of Alaska that have never been searched for Gyrfalcons. Searches of predicted nest range also will provide data about nesting phenology, nest site features, nest substrates, etc., which can be used to refine occupancy models and improve survey designs (MacKenzie et al. 2006). 
Figure 1. Predicted distribution of nesting Gyrfalcons in Alaska. Part of southeast Alaska and the Aleutian Islands are not shown in this map because these areas are in the lowest prediction category.

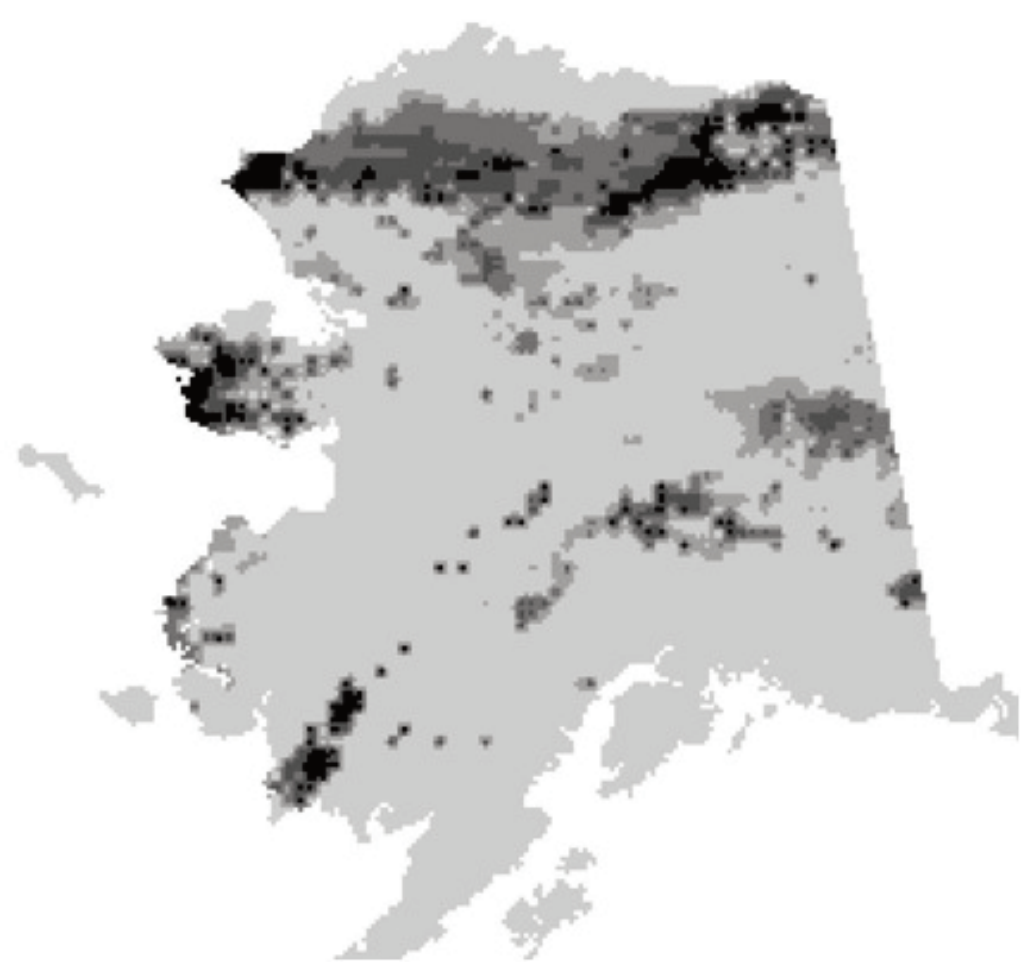

Gyrfalcons at one of the YDNWR study areas showed low, but statistically significant genetic differentiation from those in the other two study areas. Furthermore, Gyrfalcons in the three study areas returned to nest in the study area in which they were first detected breeding, with no detected breeding dispersal and only one case of natal dispersal among the areas (Booms et al. 2011a). These results suggest that additional sampling should be conducted to ascertain the extent of genetic structure among Alaskan Gyrfalcons. Genetic structure is an important consideration for wildlife conservation (Frankham et al. 2002, Wagner et al. 2005), and monitoring Gyrfalcons that exhibit different structure might be warranted.

Our survey results, and analysis of those of Swem et al. (1994) and Shank and Poole (1994), suggest that occupancy estimation of
Gyrfalcon nesting might be a relatively practical method for monitoring the species in Alaska. Survey results from multiple areas, such as the Colville River (Swem and Matz 2011), Seward Peninsula (Bente 2011), Denali National Park (C. McIntyre pers. com.), and Yukon Delta National Wildlife Refuge (McCaffery et al.2011), will be invaluable for monitoring. Furthermore, predictive modeling (Booms et al. 2009) indicates regions that should be searched for nesting Gyrfalcons, and there are additional areas where previous survey results (e.g., White and Streater 1971, Mindell and Dotson 1982, Ritchie et al. 2003) will be informative for developing a monitoring sample design.

Additional information is needed for designing a thorough, practical, state-wide monitoring plan. We suggest that the next steps toward a comprehensive monitoring plan could be: 
- The Alaska Raptor Group identifies specific areas in the state that should receive the highest priority for long-term monitoring, as recommended in Schempf (2000). These "index" or "legacy" areas should be identified based on the presence of long-term historical data sets, current knowledge of populations, ability to survey for multiple cliff-nesting raptors simultaneously, and logistical feasibility.

- Conduct surveys designed to gather data for estimating probability of detection for ongoing surveys and methods.

- Use a dual frame sample design (Haines and Pollock 1998) or similar approach in which sample plots or transects that include some historical nest sites and adjacent potential breeding habitat are searched, which is required to monitor for additional nesting and shifts in nest area use.

- Search new areas, based on the model predictions of where nesting will occur.

- Gather data about:

- nesting phenology,

- landscape features associated with the search areas,

- nest site characteristics, and

- other species of interest.

- Gather samples (e.g., molted feathers, blood) for analysis for genetic structure, disease, and contaminants.

- Establish one common, secure database for statewide survey data to allow for metaanalyses and archiving, and establish appropriate policies defining its use, along with each participating entity's roles and responsibilities in its use.

A comprehensive monitoring plan for Gyrfalcons will depend on coordinated surveys among biologists and among organizations to ensure that quality results are archived in a common, secure database to allow for statewide meta-analysis. The need for cooperative efforts to address raptor research and management has long been recognized (Schempf and Fuller 1982) and is being pursued by the Alaska Raptor Group. An extensive, coordinated effort for Gyrfalcons can begin now, building on previous surveys and increasing coverage of Alaska, and can be designed to concurrently include other cliffnesting raptors to increase cost effectiveness.

Research is required to learn if there are differences within regions that could affect the survey designs, interpretation of survey and monitoring results, and conclusions about population status. Some of the relevant topics for research are dispersal, site fidelity, and predator-prey relationships (e.g., Nielsen and Cade 1999, Booms and Fuller 2003), especially fluctuations of ptarmigan and how they affect Gyrfalcon nest area occupancy, reproduction, and survival (Barichello and Mossop 2011, Falkdalen et al. 2011, Potapov 2011). Monitoring and research of Gyrfalcons in Alaska can contribute to conservation of this raptor and to understanding and responding to the changes coming to high latitude plant and wildlife communities (Booms et al. 2011b, Cade 2011, Huntley and Green 2011, Matz et al. 2011, Mossop 2011).

\section{ACKNOWLEDGMENTS}

We are grateful for the many persons who shared their experience and ideas about surveys and monitoring. We thank Kristin Hasselblad for helping assemble and analyze historical information. We thank Tom Doolittle, Brian McCaffery, Carol McIntyre, Ted Swem, and Kim Titus, and the Alaska Raptor Group for productive and informative discussions. Steve Lewis and Rick Watson provided helpful reviews of a manuscript. 


\section{Literature Cited}

Ambrose, R. E., R. J. Ritchie, C. M. White, P. F. SCHEMPF, T. SWEM, AND R. DitTRICK. 1988. Changes in the status of Peregrine Falcon populations in Alaska. Pages 73-82 in T. J. Cade, J. H. Enderson, C. G. Thelander, and C. M. White (Eds.). Peregrine Falcon Populations: Their Management and Recovery. The Peregrine Fund, Boise, Idaho, USA.

Barichello, N., AND D. Mossop. 2011. The overwhelming influence of ptarmigan abundance on Gyrfalcon reproductive success in the central Yukon, Canada. In R. T. Watson, T. J. Cade, M. Fuller, G. Hunt, and E. Potapov (Eds.). Gyrfalcons and Ptarmigan in a Changing World. The Peregrine Fund, Boise, Idaho, USA. http://dx.doi.org/ 10.4080/gpcw.2011.0205

BenTE, P. J. 2011. Abundance and multi-year occupancy of Gyrfalcons Falco rusticolus on the Seward Peninsula, Alaska. In R. T. Watson, T. J. Cade, M. Fuller, G. Hunt, and E. Potapov (Eds.). Gyrfalcons and Ptarmigan in a Changing World. The Peregrine Fund, Boise, Idaho, USA. http://dx.doi.org/ 10.4080/gpcw.2011.0204

Booms, T. L. 2010. Gyrfalcon breeding biology in Alaska. Ph.D. thesis, University of Alaska Fairbanks. Alaska, USA. 219 pages; AAT 3436655.

Booms, T. L., T. J. CADE, AND N. J. Clum. 2008a. Gyrfalcon (Falco rusticolus). In A. Poole (Ed.). The Birds of North America Online. Cornell Laboratory of Ornithology, Ithaca, New York, USA. Retrieved from The Birds of North America Online database: http://bna.birds.cornell.edu/bna/ species/114

Booms, T. L., AND M. R. Fuller. 2003. Gyrfalcon diet in central West Greenland during the nesting period. Condor 105:528-537.

Booms, T. L., F. Huettmann, and P. F. SCHEMPF. 2009. Gyrfalcon nest distribution in Alaska based on a predictive GIS model. Polar Biology: 33:347-358.
Booms, T., M. LindGRen, AND F. HuetTMAnN. 2011b. Linking Alaska's predicted climate, Gyrfalcon, and ptarmigan distributions in space and time: A unique 200-year perspective. In R. T. Watson, T. J. Cade, M. Fuller, G. Hunt, and E. Potapov (Eds.). Gyrfalcons and Ptarmigan in a Changing World. The Peregrine Fund, Boise, Idaho, USA. http://dx.doi.org/10.4080/gpcw.2011.0116

BOOMS, T., B. MCCAFFERY, AND P. SCHEMPF. 2008b. Molted-feather persistence and aging in a sub-arctic environment: Implications for noninvasive genetic sampling. Condor 110:756-762.

Booms, T. L., P. F. SCHEMPF, B. J. MCCAFFERY, M. S. LindBERG, AND M. R. Fuller. 2010. Detection probability of cliff-nesting raptors during helicopter and fixed-wing aircraft surveys in western Alaska. Journal of Raptor Research 44:175-187.

Booms, T. L., S. L. Talbot, G. K. Sage, B. J. MCCAFFERY, K. G. MCCRACKEN, AND P. F. SCHEMPF. 2011a. Nest-site fidelity and dispersal of Gyrfalcons estimated by noninvasive genetic sampling. Condor 113(4): 768-778.

CAdE, T. J. 1960. Ecology of the Peregrine and Gyrfalcon populations in Alaska. University of California Publications in Zoology 63:151-290.

CAdE, T. J. 2011. Biological traits of the Gyrfalcon (Falco rusticolus) in relation to climate change. In R. T. Watson, T. J. Cade, M. Fuller, G. Hunt, and E. Potapov (Eds.). Gyrfalcons and Ptarmigan in a Changing World. The Peregrine Fund, Boise, Idaho, USA. http://dx.doi.org/10.4080/gpcw.2011. 0104

FALKdalen, U., M. HöRnell-Willebrand, T. NygÅrD, T. Bergström, G. Lind, A. NoRDIN, AND B. WARENSJÖ. 2011. Relations between Willow Ptarmigan (Lagopus lagopus) density and Gyrfalcon (Falco rusticolus) breeding performance in Sweden. Extended abstract in R. T. Watson, T. J. Cade, M. Fuller, G. Hunt, and E. Potapov (Eds.). Gyrfalcons and Ptarmigan in a Changing World. The Peregrine Fund, 
Boise, Idaho, USA. http://dx.doi.org/ 10.4080/gpcw.2011.0217

Frankham, R., J. D. Ballou, and D. A. BRISCOE. 2002. Introduction to Conservation Genetics. Cambridge University Press, Cambridge, UK.

GeISSLER, P. H., AND M. R. Fuller. 1986. Estimation of the proportion of an area occupied by an animal species. Pages 533-538 in Proceedings of the Section on Survey Research Methods of the American Statistical Association. American Statistical Association, Alexandria, Virginia, USA.

Haines, D. E., AND K. H. Pollock. 1998. Estimating the number of active and successful bald eagle nests: An application of the dual frame method. Environmental and Ecological Statistics 5:245-256.

Huntley, B., AND R. E. GREEN. 2011. The utility of bioclimatic models for projecting future changes in the distribution of birds in response to climate change. In R. T. Watson, T. J. Cade, M. Fuller, G. Hunt, and E. Potapov (Eds.). Gyrfalcons and Ptarmigan in a Changing World. The Peregrine Fund, Boise, Idaho, USA. http://dx.doi.org/ 10.4080/gpcw.2011.0111

LEWIS, S. A., AND W. R. Gould. 2000. Survey effort effects on power to detect trends in raptor migration counts. Wildlife Society Bulletin 28:317-329.

MacKenzie, D. I., J. D. Nichols, J. A. Royle, K. H. Pollock, L. A. Bailey, And J. E. HINES. 2006. Occupancy Estimation and Modeling: Infering Patterns and Dynamics of Species Occurrence. Elsevier, San Diego, California, USA.

Matz, A., T. Swem, P. Johnson, T. Booms, AND C. White. 2011. Potential for climate change to increase contaminants exposure and effects in Gyrfalcons. In R. T. Watson, T. J. Cade, M. Fuller, G. Hunt, and E. Potapov (Eds.). Gyrfalcons and Ptarmigan in a Changing World. The Peregrine Fund, Boise, Idaho, USA. http://dx.doi.org/ 10.4080/gpcw.2011.0115

MCCAFfery, B. J., T. L. Booms, T. C. J. Doolittle, F. Broerman, J. R. Morgart,
AND K. M. Sowl. 2011. The ecology of Gyrfalcons Falco rusticolus on the YukonKuskokwim Delta, Alaska. In R. T. Watson, T. J. Cade, M. Fuller, G. Hunt, and E. Potapov (Eds.). Gyrfalcons and Ptarmigan in a Changing World. The Peregrine Fund, Boise, Idaho, USA. http://dx.doi.org/ 10.4080/gpcw.2011.0117

Mindell, D. P., AND R. A. Dotson. 1982. Distribution and abundance of nesting raptors in southwestern Alaska. Pages 112-137 in W. N. Ladd and P. F. Schempf (Eds.). Raptor Management and Biology in Alaska and Western Canada: Proceedings of a Symposium and Workshop, 17-20 February 1981, Anchorage, Alaska. FWS/AK/PROC-82. USDI, USFWS, Anchorage, Alaska, USA. Mossop, D. H. 2011. Long-term studies of Willow Ptarmigan and Gyrfalcon in the Yukon Territory: A collapsing 10-year cycle and its apparent effect on the top predator. In R. T. Watson, T. J. Cade, M. Fuller, G. Hunt, and E. Potapov (Eds.). Gyrfalcons and ptarmigan in a changing world. The Peregrine Fund, Boise, Idaho, USA. http:// dx.doi.org/10.4080/gpcw.2011.0206

Mossop, D. H., AND R. HAYEs. 1994. Long term trends in the breeding density and productivity of Gyrfalcon (Falco rusticolus) in the Yukon Territory, Canada. Pages 403413 in B.-U. Meyburg and R. D. Chancellor (Eds.). Raptor Conservation Today. WWGBP, The Pica Press, Berlin, Germany. Nielsen, Ó. K., And T. J. CAde. 1999. Seasonal changes in food habits of Gyrfalcons in NE-Iceland. Ornis Scandinavica 21:202211.

Potapov, E. 2011. Gyrfalcon diet: Spatial and temporal variation. In R. T. Watson, T. J. Cade, M. Fuller, G. Hunt, and E. Potapov (Eds.). Gyrfalcons and Ptarmigan in a Changing World. The Peregrine Fund, Boise, Idaho, USA. http://dx.doi.org/ 10.4080/gpcw.2011.0106

Ritchie, R. J., A. M. Wildman, And D. A. YoKel. 2003. Aerial surveys of cliff-nesting raptors in the National Petroleum Reserve-Alaska, 1999, with comparisons to 
1977. Technical note 413. US Department of the Interior, Bureau of Land Management, Fairbanks, Alaska, USA.

RoseneAU, D. G. 1972. Summer distribution, numbers, and food habits of the Gyrfalcon (Falco rusticolus L.) on the Seward Peninsula, Alaska. M.S. thesis, University of Alaska, Fairbanks, Alaska, USA.

SCHEMPF, P. F. 2000. Management plan for Alaskan raptors. US Fish and Wildlife Service Report, Juneau, Alaska, USA.

SCHEMPF, P. F., AND M. R. Fuller. 1982. A workshop on raptor management and biology in Alaska and western Canada - a summary. Pages 305-318 in W. N. Ladd and P. F. Schempf (Eds.). Proceedings of the Symposium: Raptor Management and Biology in Alaska and western Canada. US Fish and Wildlife Service, Anchorage, Alaska, USA.

Shank, C. C., AND K. G. PoOle. 1994. Status of Gyrfalcon Falco rusticolus populations in the Northwest Territories, Canada. Pages 421-436 in B.-U. Meyburg and R. D. Chancellor (Eds.). Raptor Conservation Today. World Working Group on Birds of Prey, Pica Press, Berlin, Germany.

Swem, T., AND A. Matz. 2011. Observations of Gyrfalcons along the Colville River, Alaska, 1981-2005. In R. T. Watson, T. J. Cade, M. Fuller, G. Hunt, and E. Potapov (Eds.). Gyrfalcons and Ptarmigan in a Changing World. The Peregrine Fund,
Boise, Idaho, USA. http://dx.doi.org/ 10.4080/gpcw.2011.0120

Swem, T., C. Mcintyre, R. J. Ritchie, P. J. Bente, AND D. G. Roseneau. 1994. Distribution, abundance, and notes on the breeding biology of Gyrfalcons Falco rusticolus in Alaska. Pages 437-444 in B.-U. Meyburg and R. D. Chancellor (Eds.). Raptor Conservation Today. World Working Group on Birds of Prey, Pica Press, Berlin, Germany.

Wagner, R. S., M. P. Miller, C. Crisafulli, AND S. M. HAIG. 2005. Geographic variation, genetic structure, and conservation unit designation in the Larch Mountain Salamander (Plethodon larselli). Canadian Journal of Zoology 83:396-406.

White, C. M., And S. K. Sherrod. 1973. Advantages and disadvantages of the use of rotor-winged aircraft in raptor surveys. Raptor Research 7:97-104.

White, C. M., AND H. K. Springer. 1965. Notes on the Gyrfalcon in western coastal Alaska. Auk 82:104-105.

White, C. M., AND J. H. STREATER. 1971. Survey of raptorial birds along the proposed Trans-Alaska Pipeline System. Raptor Research News 5:96-99.

Williams, B. K., J. D. Nichols, AND M. J. Conroy. 2002. Analysis and Management of Animal Populations. Academic Press, San Diego, California, USA. 